\title{
The Effect of the Perceived Buzz of Instagram's Post on the Rewatching Intention of Broadcasting Contents: Mediating Emotional Engagement
}

\author{
Mikyung Kim ${ }^{1}$ \\ ${ }^{1}$ Professor, Media Communication Department, Chungwoon University, S. Korea, \\ mkqueen67@gmail.com
}

\begin{abstract}
This study is aimed to examine how the perceived buzz of broadcasting programs on Instagram affects the intention of rewatching programs and mediating emotional engagement. Instagram is a social media that plays an important role in appealing content brands to young people. Broadcasting companies are also using Instagram to increase the brand value of broadcasting contents. Moreover, social media such as Instagram can trigger emotions through various emoticons. On Instagram, users' perception of buzz of the drama through post will affect the change in attitude, but users' emotional attributes will be mediated. This study produced an Instagram post of seven types (framed type, clip video, character, viewing rate news, broadcast-time-notice, pictorial, event) about the drama of "When Camellia Blooms". The survey was conducted on 122 adults using Instagram, and utilized the PROCESS macro to perform a mediated analysis. Based on the results, it was found that if Instagram posts become a hot topic to people, they will rewatch broadcasting programs, and if they reflect elements of positive emotions on Instagram posts, they will have an impact. Thus, this suggests that attitude changes affect the perceived buzz and mediated positive emotion attributes on Instagram. Giving emotional attributes such as emoticons on Instagram will be an important factor in increasing loyalty and changing attitudes.
\end{abstract}

Keywords: Instagram, Perceived Buzz, Rewatching Intention, Positive Emotion, Negative Emotion

\section{Introduction}

Users' media usage behavior is currently changing significantly from analog to digital. In the digital age, the excess of information increases the user's fatigue, but so does the interest in specific information. Therefore, the attention of certain information is changing depending on the characteristics of the platform. Instagram is a social media platform that has grown into image-oriented content favored by young people. As personal interaction becomes active on Instagram depending on young people's hobbies and interests, companies are using Instagram to gain branding effects[1]. Instagram is using it for marketing because users can spread posts with hashtags(\#). Through this, it forms a long-term brand image and naturally reaches the brand domain. In addition, location tagging or region tagging increases participation. Instagram further analyzes hashtags for brand accounts that users follow or photos that click "like." It will introduce new products that users will be interested in.

Emoticons on social media affect users' emotions and are being used in brand marketing. Emotional 
emoticons are used for marketing on Instagram, and it is very curious what the impact of brand marketing will be like if it mediates emotions. This is because if the current state of actual user emotions is used for brand marketing, customized marketing based on taste, interest, and sensibility is possible. Therefore, this study found that television uses Instagram as a means of promoting broadcasting programs, and seeks to examine how broadcasting programs are promoted on Instagram. Television uses social media such as Instagram as a means of showing behind-the-scenes stories[2], but broadcasters now use Instagram to enhance content brand visibility and interact with young people. Old media such as "The Guardian" are also using social media to increase content brand value and spread news[3]. As such, old media is using Instagram to promote the brand of content. This paper examines how users' perceptions of topic actually affect content consumption. The perceived buzz, an independent variable for this study, is about the buzz of content perceived by Instagram users when old media posts content using Instagram. This topicality is a similar concept to visibility which is the concept of how prominent a particular program is in the media. This visibility causes users to comment on content and becomes a topic of conversation. In previous studies, if the perceived buzz has important impact on user's attitudes, this experimental study aims to see that Instagram's perceived buzz can be mediated by emotions and the importance of the issue can be assessed higher. Furthermore, this study is intended to raise the importance of combining cognitive perception and emotion on social media such as Instagram.

This study examines how the perceived buzz about the drama content of "When the Camellia Blooms" actually affects rewatching the content. In addition, various emoticons on Instagram create feelings for broadcasting companies' posts, and how their reactions affect users' feelings about content and how they affect their intention to rewatch it. To this end, this study produces various experimental posts for the drama "When the Camellia Blooms" and examines the rewatching according to the user's feelings. This study seeks to understand the effectiveness of Instagram's drama promotion and to mention that emotions are important in marketing.

\section{Literature Review}

\subsection{Instagram and the Promotion Strategy of Buzz}

Instagram is a mobile application that has more than 400 million active users around the world. Approximately eighty million photos are shared daily[4]. Most active users live in the United States (25\%), Europe (16\%), and the Asia-Pacific region (16\%). Instagram focuses on an image, video, and textual content that allows a connection with fans of the brand. In a study conducted by Lavoie[5], content related to a brand that is generated on Instagram is associated with the brand through emotions represented by funny images and positive messages. It is possible that feelings of connection and happiness can be transmitted through Instagram[6] since reality embodied in images greatly satisfies and influences followers of social networks. Legacy media uses social media to improve brand visibility and interact with younger people to promote the program's buzz and measure their responses. Many broadcasters believe that creating a buzz through social media will help increase viewership and preserve advertising revenue. For example, NBC's Chuck faced a crisis of suspension due to falling ratings but overcame it through a Twitter campaign. Previous studies show that social media has a greater impact on specialized or niche programs watched by a small number of people with strong loyalties than popular programs watched by many people[7].

This is because spreading a lot of information about the program on Instagram affects viewing ratings. Program buzz is a concept like visibility. Program visibility means how prominent a particular program is in the media. The buzz of a program can be defined as how much media and users refer to the program or information about the program. The perceived buzz refers to a state in which users 
perceived the buzz of a program.

In fact, previous studies have shown that media coverage and users' buzz are correlated with the number of video views[8]. It also said that reporting on programs aired by the media affects users to share and spread the programs[9].

This study looks at how the user's awareness of the program, which saw the broadcast program posts on Instagram, is related to watching terrestrial programs.

Hypothesis 1: On Instagram, the user's perceived buzz of a broadcast program will affect the intention of rewatching the program.

\subsection{Emotion Engagement and Rewatching Intention}

Emotions are also considered to create experiences of engaging in social media campaign. It has also emphasized the transition to influential contents by mixing information, opinions, emotions and personal experiences in the current media environment[10]. As the marketing world loves to talk about "points of engagement" between a brand and a (potential) consumer, contents production should consider emotion to create the experience of involvement with online campaign. As Peters[11] shows, contents have always been emotional - the difference today is a growing diversity of emotional styles, the increased acceptability of user's participation, and how attempts to involve the audience have become more explicit. Previous studies have also shown that the emotion promotes sharing of emotions, leading to pressing the shared button[12]. Visual images on Instagram are more intuitive and emotional than textual information, so they change attitudes, intentions and behaviors afterwards depending on what consumers' feelings are like as soon as they see the image. Especially the emotional involvement in content campaigns result in "reading, watching, viewing, listening, checking, snacking, monitoring, scanning, searching, clicking, linking, sharing, liking, recommending, commenting and voting"[13].

There have been several existing studies on the role of emotion. First of all, the study of news contents usage and emotional response[14] and the study of emotional word-inducing effects used in news contents shows close relationship between emotion and cognitive processes. It is also found that the media plays an important role in arousing emotions and that different types of individual emotions can be triggered according to media messages. Next, research on emotion and political participation[15] shows that the political judgment and actions of voters are based on both rational and emotional responses, and the media plays an important role in arousing voter sentiment. Meanwhile, the study of emotional connection in marketing[16][17] is an important online marketing element, taking into account that emotion is a significant source of online marketing. It also proved that emotions are essential to promote the participation of members of the brand community on social networking sites[18].

Emotion drives people's increasingly intimate relationships with technology, fuels engagement with news and information, and inspires professionals to pursue careers in an industry that offers anything but reliable rewards for work well done. It inspires connection. As journalism and society change, emotion is becoming a much more important dynamic in how news is produced and consumed. Emphasizing emotion as the key redefines the classic idea of journalistic objectivity-indeed, it is reshaping the idea of news itself.

User engagement refers to the extent to which users interact with targeted content and have psychological or behavioral relationships[19]. User content management is very important in terms of corporate marketing because it is a measure of how actively users participate in content brand activities of a particular company[20][21]. The higher the user's participation, the greater the relationship with the users, as well as the greater the viral effect of using posts. In a social media environment, users can click the Like button on a content post, share the contents of a post, or write a 
comment on a post. Also, emotional entertainment can affect the use and loyalty of the content.

This study looks at whether the perceived buzz of broadcasting programs is more likely to be used and to strengthen the user's willingness to rewatch by emotional engagement. Thus, the following hypotheses were established.

Hypothesis 2: The perceived buzz of broadcasting programs will affect the watching intention of broadcast program through the medium of emotional entertainment.

H 2-1: The perceived buzz of broadcasting programs will affect the watching intention of broadcast program through the medium of positive emotional entertainment.

$\mathrm{H}$ 2-2: The perceived buzz of broadcasting programs will affect the watching intention of broadcast program through the medium of negative emotional entertainment.

\section{Research Methodology}

\subsection{Measurement}

\subsubsection{Dependent Variable: Rewatching Intention}

Watching intention is to see if they are willing to watch broadcasting programs on various platforms. This variable is composed of the following: "Would you search for related articles and social media after watching the topical posts of Instagram's broadcast program? ," "Do you arouse curiosity about the program," "Do you want to watch the main broadcast, rerun and video on demand(VOD) of program," and "Do you want to recommend the program to your friend?" Four questions are composed of a five-point scale. (' 1 ' is Not at all and ' 5 ' is 'Very much so'). Analysis of the reliability of viewing intentions is $\alpha=.960$.

\subsubsection{Independent Variable: The Perceived Buzz}

In this study, we would like to examine how the perception of the buzz of broadcast program impact on the intention of viewing. The buzz is a measure of how much information related to a particular TV program was generated online, and how much netizens paid attention to the information (Lee J.H, 2018). However, although the measurement index of buzz is used as comments on portal site articles, social media posts, various community posts and comments, "like" on clip videos, and search frequency, no unified indicators have been found yet.

In this study, the buzz was defined as 'people's interest and reference' and the perceived buzz was defined as 'recognizing popularity with people's interest'. In order to measure the perceived buzz of the post of broadcast program, <When the Camellia Blooms>, seven broadcasting program posts were viewed and then the following questions were answered. Do you think the "When the Camellia Blooms" program is a hit? Did you notice the number of likes in the program "When the Camellia Blooms?" Do you think the "When the Camellia Blooms" program is popular? Three questions are composed of a five-point scale. (' 1 ' is Not at all and ' 5 ' is 'Very much so'). Analysis of the perceived buzz is $\alpha=.853$.

\subsubsection{Mediation Variables: Positive Emotional Engagement, Negative Emotional ngagement}

In this study, the emotional response to broadcast program postings was measured. Emotional responses were defined as favorable responses to the posts, and the emotional responses of the drama "When the Camellia Blooms" were measured. The viewing attitude used by Yoo, et al (2004) and Kim et al (2009) was also reconstructed according to the purpose of the study, referring to 10 questions. The questions for positive emotional engagement are composed of 'It is pleasing', 'It is new' and It is favorable'. Analysis of reliability of positive emotional engagement is $\alpha=.903$. The questions for 
negative engagement are composed of 'It is boring', 'It is not pleasing', 'It is annoying'. Analysis of reliability of negative emotional engagement is, $\alpha=.846$

\subsection{Data Collection}

The survey was conducted on "2049 (20-49-year-old viewers)" that advertisers consider as a key target group. A total of 125 surveys questionnaires were retrieved, and the final 122 copies of the were subjected for analysis, excluding the three with insincere responses. It was held online for four days from November 27 to 30, 2019. The subjects were selected by convenience sampling, and were limited to adults living in the metropolitan area such as Seoul, Incheon, and Gyeonggi-do. This study produced an Instagram post of seven types (framed type, clip video, character, viewing rate news, broadcast-time-notice, pictorial, event) about the drama of "When Camellia Blooms". Each experiment was asked to answer the question. Before conducting the survey, the subjects were checked whether they used Instagram within the last month. The survey was conducted only for those who use Instagram. The subjects answered the questions in the order of whether they used Instagram within the last month, Instagram usage behavior, factors that affect the viewing of posts, factors that affect sharing, Instagram usage status of broadcaster's posts, and demographic characteristics.

[Table 1] Demographical Data

\begin{tabular}{|c|c|c|c|}
\hline \multicolumn{2}{|c|}{ Demographical Characteristic } & \multirow{2}{*}{$\begin{array}{c}\text { Case number(person) } \\
33\end{array}$} & \multirow{2}{*}{$\begin{array}{c}\operatorname{Percent}(\%) \\
27.0\end{array}$} \\
\hline C & Male & & \\
\hline Geriuet & Female & 89 & 73.0 \\
\hline \multirow{4}{*}{ Age } & 20 's & 72 & 59.0 \\
\hline & 30 's & 47 & 38.5 \\
\hline & 40 's & 2 & 1.6 \\
\hline & 50 's & 1 & 0.8 \\
\hline \multirow{3}{*}{ Education } & High school & 14 & 11.5 \\
\hline & University & 103 & 84.4 \\
\hline & Graduate school & 5 & 4.1 \\
\hline \multirow{3}{*}{$\begin{array}{c}\text { Instagram subscription } \\
\text { period }\end{array}$} & Less than 1 year & 15 & 12.3 \\
\hline & More than 1 year & 22 & 18.0 \\
\hline & More than 2 years & 85 & 69.7 \\
\hline \multirow{4}{*}{ Connection frequency } & Everyday & 87 & 71.3 \\
\hline & 1 to 2 times a week & 15 & 12.3 \\
\hline & 4 to 6 times a week & 7 & 5.7 \\
\hline & 1 to 5 times a month & 13 & 10.7 \\
\hline
\end{tabular}

The TV drama "When the Camellia Blooms" was used to produce Instagram posts for a broadcasting company. There were seven types of posts produced (framed type, clip video, character, viewing rate news, broadcast-time-notice, pictorial, event). After looking at these posts, we first investigated whether users perceived the buzz of the drama "When the Camellia Blooms," and investigated the emotional state and the viewing intention of the program. 7 Post treatments for Instagram of broadcasting programs to verify the perception of buzz were each produced with the purpose presented in the following table 2. The 'like' number presented 3910 in all types of production posts. 
[Table 2] The treatments of Instagram Post of TV drama "When the Camellia Blooms"

\begin{tabular}{|c|c|c|}
\hline Type of post & Message of post & The number of 'like' \\
\hline Frame & Program image immersion and concentration & 3910 \\
\hline Clip video & Identify program topics or content & 3910 \\
\hline Character & character fandom formation & 3910 \\
\hline Viewing rate news & reputation and viral marketing & 3910 \\
\hline Broadcast time notice & Attract viewers with conflict messages & 3910 \\
\hline Pictorial & Presenting the Emotional Image of Lovers & 3910 \\
\hline Event & Induce participation and interactivity & 3910 \\
\hline
\end{tabular}

\subsection{Data Analysis}

The data analysis of this study was conducted using SPSS 20.0 to verify the normal distribution of variables included in the study model. Frequency and percentages were calculated to identify the general characteristics of the survey subjects. Descriptive statistics, skewness and kurtosis were calculated to confirm multivariate normality for the major variables. The Cronbach's $\alpha$ coefficient was calculated for reliability analysis. This method shows verification results at a time when a related variable is entered with bootstrapping, which can be estimated simultaneously in a single model, because there is a correlation between the parameters when two or more parameters exist in an independent variable and a dependent variable investigation. This has the advantage of not having to go through various procedures, and a new analysis method called Process macro is being spread as a method of verifying the medium effect. I installed Process v3.3 on SPSS/Win 20.0 for mediation analysis, and used it through Model No. 4, proposed by Hayes[22]. To verify the significance of the study model, the bootstrapping method was used to re-sample 10,000 times and the variables put in were mean-centering. The significance verification used a $95 \%$ confidence interval and was determined to be statistically significant when ' 0 ' was not included between confidence intervals. The signification of mediation effect and the size of its influence were verified by comparing the differences in the three paths, i.e., the effect values for paths with only primary parameters, paths with only secondary parameters, and paths with both primary and secondary parameters.

\section{Research Result}

\subsection{Descriptive Statistics and Correlation of Variables}

The results of the basic descriptive analysis of perceived buzz, positive emotion, negative emotion and watching intention, which are the main variables presented in the research model and research questions of this study, are presented in Table 3. The mediated effect obtained from the 95\% confidence interval was verified. The absolute values of the skewness value of the variables was less than .218 and the absolute value of the kurtosis value as less than .001 . This satisfies the criteria of the normal distribution presented in Klein[23] for skewness values $( \pm 3)$ and kurtosis values $( \pm 10)$, so there is no problem with normality, Table 3.

The results of the correlation analysis to determine the degree of correlation of variables considered in this research question are as shown in Table 4. In the relation between the perceived buzz and rewatching intention, the higher the perceived buzz, the more positive relation with the rewatching intention $(\mathrm{r}=.634, \mathrm{p}<.01)$ was. The perceive buzz and positive emotion $(\mathrm{r}=.721 \mathrm{p}<) .01)$ showed a positive correlation. The perceived buzz and negative emotion did not show any correlation ( $\mathrm{r}=-.058$, $\mathrm{p}=.523)$. Also, positive emotion and negative emotion are negative relation $(\mathrm{r}=-.214, \mathrm{p}<.01)$. Finally, 
there was no correlation between negative emotion and viewing intention $(\mathrm{r}=.120, \mathrm{p}=.189)$. These should be brief and placed at the end of the text before the references.

[Table 3] Mean and SD, Skewness and Kurtosis of Measurement Variables

\begin{tabular}{|c|c|c|c|c|c|c|}
\hline & $\begin{array}{c}\text { minimum } \\
\text { value }\end{array}$ & maximum value & mean & SD & Skewness & Kurtosis \\
\hline Rewatching intention & 1.00 & 5.00 & 2.598 & 1.1829 & .218 & -.757 \\
\hline Perceived buzz & 1.00 & 5.00 & 2.918 & 1.2371 & -.082 & -.879 \\
\hline Positive emotion & 1.00 & 5.00 & 3.254 & 1.0169 & -.243 & .001 \\
\hline Negative emotion & 1.00 & 4.00 & 1.975 & .9223 & -.306 & -1.234 \\
\hline
\end{tabular}

[Table 4] The Correlation of Variables

\begin{tabular}{|c|c|c|c|c|}
\hline & Perceived buzz & $\begin{array}{c}\text { Positive } \\
\text { emotion }\end{array}$ & Negative emotion & Watching intention \\
\hline Perceived buzz & 1 & & & \\
\hline Positive emotion & $.634 * *$ & 1 & 1 & \\
\hline Negative emotion & -.009 & $-.214 * *$ & .120 & 1 \\
\hline Rewatching intention & $.734 * *$ & $.532^{* *}$ & \\
\hline
\end{tabular}

$* \mathrm{p}<.05, * * \mathrm{p}<.01, * * * \mathrm{p}<.001$

\subsection{Mediation Result using PROCESS Macro}

The analysis was conducted using Process macro, Model No. 4 proposed by Hayes (2018) to verify the mediation effects of positive and negative emotions in the relationship between perceived buzz and rewatching intention. As a result of the analysis, perceived buzz had a significant positive effect on positive emotion $(\beta=.521, \mathrm{p}<.001)$, Positive emotion also had a significant effect on the rewatching intention $(\beta=.195 \mathrm{p}<.05)$. The perceived buzz did not have a significant effect on negative emotions $(\beta=-.007, p=.9214)$. However, negative emotions were shown to have a significant effect on rewatching intentions $(\beta=.207, \mathrm{p}<.05)$. Meanwhile, the total path effect between perceived buzz and rewatching intention is $\beta=.702(\mathrm{p}<.001)$. However, the total effect of the path between the perceived buzz and the rewatching intention is reduced by direct effect $(\beta=.602(\mathrm{p}<.001)$ after the mediation variables, positive and negative emotion were put in. Positive emotions were found to be mediated in the relationship between perceived buzz and rewatching intention.

[Table 5] The Mediation Effects of Positive and Negative Emotions in the Relationship between Perceived Buzz and Rewatching Intention

\begin{tabular}{|c|c|c|c|c|c|c|}
\hline Variables & $\beta$ & se & T value & $\mathbf{p}$ & LLCI* & ULCI $^{* * *}$ \\
\hline \multicolumn{7}{|c|}{ Mediation Variable Model (Dependent Variable: Positive emotion) } \\
\hline Constant & 1.7328 & .1838 & 9.4298 & .0000 & 1.3690 & 2.0967 \\
\hline Perceived buzz & .5213 & .0580 & 8.9862 & .0000 & .4065 & .6362 \\
\hline \multicolumn{7}{|c|}{ Mediation Variable Model (Dependent Variable: negative emotion) } \\
\hline Constant & 1.9950 & .2156 & 9.2552 & .0000 & 1.5682 & 2.4218 \\
\hline Perceived buzz & -.0067 & .0681 & -.0989 & .9214 & -.1415 & .1280 \\
\hline
\end{tabular}




\begin{tabular}{|c|c|c|c|c|c|c|c|}
\hline \multicolumn{7}{|c|}{ Dependent Variable Model (Dependent Variable: Rewatching Intention) } \\
\hline Constant & -.1993 & .3160 & -.6308 & .5294 & -.8251 & .4265 \\
\hline Perceived buzz & .6018 & .0757 & 7.9504 & .0000 & .4519 & .7517 \\
\hline Positive emotion & .1947 & .0943 & 2.0650 & .0411 & .0080 & .3813 \\
\hline Negative emotion & .2066 & .0804 & 2.5708 & .0114 & .0475 & .3657 \\
\hline
\end{tabular}

*LLCI=Low limit for $95 \%$ confidence interval of boot indirect effect

**ULCI=The upper limit in $95 \%$ confidence interval of boot indirect effects

[Fig. 1] is a visualization of [Table 5]. Perceived buzz has an effect to rewatching intention in the total path effect $(\beta=.702, \mathrm{p}<.001)$. But the total effect of the path between the perceived buzz and the rewatching intention is reduced by direct effect $(\beta=.602 \quad(\mathrm{p}<.001)$ after the mediation variables, positive and negative emotion were put in. Positive emotions were found to be mediated in the relationship between perceived buzz and rewatching intention. Perceived buzz has effect on positive buzz $(\beta=.521, p<.001)$. Positive emotion has effect on rewatching intention $(\beta=.195 \mathrm{p}<.05)$. But perceived buzz has no effect on negative emotion $(\beta=-.007, \mathrm{p}=.9214)$. Negative emotion has effect on rewatching intention $(\beta=.207, \mathrm{p}<.05)$.

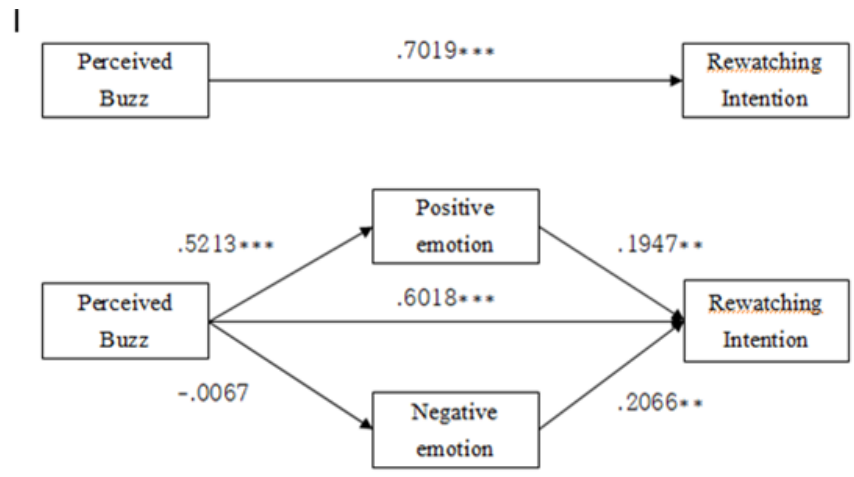

[Fig. 1] The Mediation Effects of Positive and Negative Emotions in the Relationship between Perceived Buzz and Rewatching Intention

In order to verify the mediating effect of positive and negative emotions in the relationship between perceived buzz and rewatching intentions, 5,000 bootstraps were designated using model 4 of PROCESS macro, and effects analysis was conducted by setting the confidence interval to $95 \%$. The result is as shown in Table 6. As a result of the analysis, the overall mediated effect size is .1001(.0041 .1963). This was significant because zero did not exist in the 95\% confidence interval. The positive emotion of simple mediate effect is .1015 (.0111 .1964). This was significant because zero did not exist in the $95 \%$ confidence interval. However, negative emotion is -.0014(.-.0311 ).0316). There is no mediate effect because this was not significant because zero exist in the $95 \%$ confidence interval.

[Table 6] The Indirect Mediation Effects of Positive and Negative Emotions on Viewing Intention.

\begin{tabular}{|c|c|c|c|c|}
\hline & $\boldsymbol{\beta}$ & se & LLCI & ULCI \\
\hline Total & .1001 & .0495 & .0041 & .1963 \\
\hline Positive emotion & .1015 & .0476 & .0111 & .1964 \\
\hline Negative emotion & -.0014 & .0154 & -.0311 & .0316 \\
\hline
\end{tabular}




\section{Conclusion}

This paper concludes emotions, especially positive emotion expressed in Instagram posts have been shown to affect the intention of rewatching along with awareness of topic. These results reflect Fractle's findings that emotions influence content diffusion for marketing benefit. The positive emotion of content in its emotional role in viral content studied by brand marketing consultant firm Fractle[11] is often said to stimulate the press of the share button. Providing positive emotional experiences along with the buzz of content is a necessary step for marketing. This is because the emotions people feel through social media posts make them directly share the posts. The spread and sharing of content posts is important in terms of marketing because it has a promotional effect by users.

Also, the theory of attribute agenda setting functions focuses on attributes, not issues. An attribute refers to a set of perspectives or frames. Attributes are divided into cognitive and emotional attributes. In this paper, perceived buzz is a cognitive attribute. Emotions have been shown to influence the intention of rewatching by mediated perceived buzz and audience attitude. Studies have found that positive emotional experiences receive more attention than negative emotional experiences. Across all ages and genders, the study participants reported creating positive feelings about the most popular images. Specifically, images that evoke complex emotions with contrasting emotions rather than single emotions, such as positive or negative emotions, help increase shock and response, which also strengthen enthusiasm.

Emotions combine with cognitive attributes to form perspectives and frames for drama content. The results of the study showed that perception of program buzz influenced viewing intentions, and positive emotions mediated perceived buzz and rewatching intentions. However, negative emotions were not mediated, and negative emotions influenced the intention of rewatching as independent variables. In order to promote marketing, such as sharing and spreading posts using user interaction on Instagram, it is important to include the attributes of positive emotions in the posts to form a positive perspective and frame for users. It is possible to create a user's attitude by including positive emotional attributes rather than just objective factual statements. The result that a negative emotion can affect rewatching is that emotions have a direct effect on attitude change.

Based on previous studies, emotions are a key factor in triggering user behavior. Now it is necessary to include emotional messages in cognitive messages to allow users to spread and share content on their own on social media. Emotions not only drive diffusion, but also actually change the user's attitude, causing rewatching of content. This study validates the role of emotion in changing attitudes for users' rewatching intentions. However, it has failed to diagnose the role of the medium of detailed emotions by simply distinguishing them into positive and negative emotions. The future research should first examine the effect of the combination of cognitive attributes and emotional attributes of perception of buzz on content on diffusion and sharing, and on the impact of attitude changes.

\section{References}

[1] A.O. Larsson, The News User on Social Media: A comparative study of interacting with media organizations on Facebook and Instagram, Journalism Studies, (2018). Vol.19, No.2, pp.2225-2242, DOI:10.1080/1461670X.2017.1332957

[2]http://www.poynter.org/how-tos/digital-strate-gies/214435/instagram-for-newsrooms-a-community-tool-a-report-ing-t ool-a-source-of-web-content/, May 27 (2013)

[3] https://www.inma.org/blogs/ideas/post.cfm/guardian-s-instagram-serial-strategy-engages-younger-audience, Oct 02 
[4] D. H. Kim, N. K. Seely, J. H. Jung, Do you prefer, Pinterest or Instagram? The role of image-sharing SNSs and self-monitoring in enhancing ad effectiveness. Computers in Human Behavior, (2017), Vol.70, pp.535-543, https://doi.org/10.1016/j.chb.2017.01.022

[5] K, Lavoie, Instagram and Branding: A Case Study of Dunkin' Donuts, Elon Journal of Undergraduate Research in Communications, (2015), Vol.6, No.2, pp.79-90.

[6] I. E. Erdogmus, M. Cicek, The impact of social media marketing on brand loyalty, Procedia-Social and Behavioral Sciences, (2012), Vol.58, pp.1353-1360, https://doi.org/10.1016/j.sbspro.2012.09.1119

[7] https://www.vanityfair.com/news/2011/03/a-match-made-in-hollywood, A match made in Hollywood?, (2011)

[8] M. H. Kang. A Study on the Characteristics of Value Evaluation Indexes for Television Contents, Korean Journal of Broadcasting \& Telecommunication Studies, (2018), Vol.32, No.3, pp.5-30.

[9] J. H. Hong, The Effect of Information Diffusion of Program on the Viewing Type of Web Platform Program and the Attention of the Public, The Journal of the Korea Contents Association, (2016), Vol.16, No.9, pp.751-768, https://doi.org/10.5392/JKCA.2016.16.09.751

[10] Z. Papacharissi, Affective Publics: Sentiment, Technology, and Politics, (Oxford Studies in Digital Politics), 1st Edition, New York: Oxford University Press, (2014)

[11] C. Peters, Emotion aside or emotional side? Crafting an "experience of involvement" in the news, Journalism, (2011), Vol.12, No.3, pp.297-316, https://doi.org/10.1177/1464884910388224

[12] https://www.frac.t1/the-role-of-emotions-in-viral-content/, Oct 10 (2018)

[13] I. C. Meijer, T. C. Kormelink, Checking, Sharing, Clicking and Linking, Digital Journalism, (2015), Vol.3, No.5, pp.664-679, https://doi.org/10.1080/21670811.2014.937149

[14] G. Marmor-Lavie, G. Weimann, Measuring emotional appeals in Israeli election campaigns, International Journal of Public Opinion Research, (2006), Vol.18, No.3, pp.318-339, https://doi.org/10.1093/ijpor/edh108

[15] H. Min, S. Y. Youn, A Critical Review on the Study of Online Political Participation: Focused on the Domestic and International Issues, Informatization Policy, (2015), Vol.22, No.2., pp.3-18, DOI : 10.22693/NIAIP.2015.22.2.003

[16] S. Hudson, M. S. Roth, T. J. Madden, R. Hudson. The effect of social media on emotions, brand relationship quality, and word of mouth: An empirical study of music festival attendees, Tourism Management, (2016), Vol.47, pp.68-76, https://doi.org/10.1016/j.tourman.2014.09.001

[17] L. Dessart, C. Veloutou, A. Morgan-Thomas, Capturing consumer engagement: duality, dimensionality and measurement, Journal of Marketing Management, (2016), Vol.32, No. 5-6, pp.399-426, https://doi.org/10.1080/0267257X.2015.1130738

[18] P. Lucelli Karina, C. Benoit, Rational or emotional posts on Facebook brand communities - The Mexico Starbucks Case, Retos: Revista de Ciencias Administrativas y Económicas, (2019). Vol.9, No.17 pp.109-126, http://dx.doi.org/10.17163/ret.n17.2019.07

[19] R. J. Brodie, L. D. Hollebeek, B. Jurić, A. Ilić, Customer Engagement: Conceptual Domain, Fundamental Propositions, and Implications for Research, Journal of Service Research, (2011), Vol.14, No.3, pp.252-271.

[20] H. D. Shahbaznezhad, R. Dolan, A. Tripathi, The Power of Facebook and Instagram Fans: An Exploration of Fan Comments and Their Effect on Social Media Content Strategy, Workshop on e-Business, (2017) Seoul: Korea

[21] C. Ashley, T. Truten, Creative Strategies in Social Media Marketing: An Exploratory Study of Branded Social Content and Consumer Engagement, Psychology \& Marketing, (2015), Vol.32, No.1, pp.15-27.

[22] A. F. Hayes, Partial, conditional, and moderated mediation: Quantification, inference, and interpretation, Communication $\quad$ Monographs, (2018), Vol.85, Special Issue, $\quad$ pp.4-40, https://doi.org/10.1080/03637751.2017.1352100

[23] R. B. Kline, Principle and Practice of Structural Equation Modeling (3rd ed), NY: Guilford Press, (2010) 